$$
\begin{aligned}
& a_{11} \quad \cdots a_{1, n-2} \quad 0 \quad 0
\end{aligned}
$$

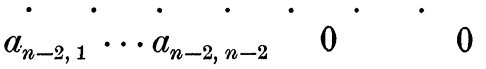

$$
\begin{aligned}
& a_{n-1,1} \cdots a_{n-1, n-2} \quad a_{n-1, n-1} 0 \\
& a_{n, 1} \quad \cdots a_{n, n-2} \quad a_{n, n-1} \quad a_{n n} \text {. }
\end{aligned}
$$

When equation (3) is integrable by quadratures this process can be continued $n$ times; the group we are considering (which is isomorphic with the group of rationality) takes the form

$$
\begin{aligned}
& a_{11} \\
& a_{21} \quad a_{22} \\
& a_{31} \quad a_{32} \quad a_{33} \\
& a_{n-1,1} \quad a_{n-1,2} \cdots a_{n-1, n-1} \\
& a_{n, 1} \quad a_{n, 2} \quad \cdots a_{n, n-1} \quad a_{n, n} \text {. }
\end{aligned}
$$

But (Lie-Engel, Transformationsgruppen I, chapter 27) the group (9) is an integrable group.

The Jordan-Beke condition for reducibility, employed above, is both necessary and sufficient. We have thus deduced as a special case of the Jordan-Beke theorem the theorem of Vessiot, namely, "the necessary and sufficient condition that a linear homogeneous differential equation shall be integrable by quadratures is that its group of rationality be integrable."

Philadelphia, Pa. August, 1902.

\title{
THE CENTENARY OF THE BIRTH OF ABEL.
}

A $\mathrm{T}$ the close of the first week in September last, the Royal Frederick University at Christiania, Norway, celebrated the one hundredth anniversary of the birth of Niels Henrik Abel. The occasion was noteworthy as the first international academic celebration in Norway and was in every way instructive and enjoyable for the delegates and guests of the university. On their arrival at the station they were met by representatives of the university who had been previously instructed as to which language each of them spoke and who conducted them to the rooms to which they had been assigned in the various hotels, 
acting the while as interpreters or informants and talking with apparent indifference French, German, English, or Norwegian. Each delegate was presented with two large volumes of which one was: Norway, the official publication of the country at the time of the Exposition at Paris in 1900, and the other: Niels Henrik Abel, Mémorial publié à l'occasion du centenaire de sa naissance, containing an ode to Abel by Bjoernson, a historical account of his life and correspondence by Holst, the letters written or received by Abel translated into French with notes and with facsimile reproductions, letters and documents relative to him likewise with notes, the original text of such letters as Abel wrote in Norwegian, and an essay by Sylow on Abel's studies and discoveries with further facsimiles. It is this volume which for most of us will probably be the most cherished and permanent monument of the celebration. There are three other volumes now publishing which may be mentioned here as memorials of the occasion and which will doubtless be of a greater value from a purely scientific point of view than those presented to us by the university. These are volumes XXVI, XXVI bis, XXVI ter, of the Acta Mathematica, which will contain recently discovered and hitherto unpublished memoirs by Abel and original memoirs by a great number of mathematicians upon those branches of mathematics in which Abel was especially interested.

Although there was an informal reception for the delegates on Thursday evening, September 4, in St. Hanshaugen Park with an introductory address of welcome by Professor Nansen, chairman of the Abel committee, the official opening of the celebration took place Friday at noon under the presidence of the rector of the university and the president of the academy of sciences. The programme consisted of a beautiful cantata composed especially for the occasion by Bjoernson and Sinding, of addresses by the minister of state and the rector of the university with responses by Professors Heinrich Weber and Volterra on behalf of the delegates, and of an address or essay by Professor Sylow on the work of Abel. Professor Sylow alone spoke in Norwegian and copies of his address translated into French were distributed among the delegates.

In the evening his majesty, King Oscar II, who in person attended the official meetings of the celebration, tendered a supper to the delegates and other invited guests. The long informal receptions before and after the supper afforded the first 
and probably the best opportunity which we had to become acquainted with one another.

On Saturday at noon the second official meeting was held under the auspices of the university. This was more of an academic, less of a state affair, than that on the preceding day. The president of the academy of sciences delivered an address. Forsyth, Gravé, Picard, Schwarz, Zeuthen responded on behalf of the delegates, Hensel for Crelle's Journal, MittagLeffler for the Acta Mathematica. The delegates then filed by and presented the inscribed congratulatory addresses or the words of felicitation sent by the various societies or universities represented.

It is difficult to obtain an exact list of the delegates, for some, Peano, Pincherle and Padé, for example, who were expected and who would have added to the already brilliant assemblage, did not arrive ; and others, as Selivanov and Knott, that one could notice came unofficially or too late to be included in the lists. The correspondents of the press give the following list taken down as the delegates filed by.

From Germany and Austria: Schwarz, H. Weber, Pringsheim, Hensel, Hilbert, Seeck, Kiepert, Fr. Meyer, Krause, Engel, Gutzmer, Lerch, Czuber. From Belgium : Mansion, Paige. From Holland: Cardinaal, Kristensen. From Denmark: Thiele, Zeuthen. From France: Picard and E. Sauvage. From America : Canfield, Olsen, Spangler, Watson (not mathematicians representing various universities), and Fields, Newcomb, Van Vleck, Wilson (the last two representing the American Mathematical Society). From Switzerland: Graf, Fehr. From Greece: Stephanos. From Russia and Finland : Lindelöf (senior), Donner, Tallqvist, Bäcklund, Zdanov, Gravé, Zantshevsky. From Sweden and Norway: A. B. Bäcklund, Wijkander, Möbius, Théel, Bendixson, von Koch, Dunér, Mittag-Leffler, Dahle, Hansen, Lugaard, Spaare. From Italy: Orland, Volterra, Del Pezzo. From Great Britain : Lamb, Love, Forsyth, Joly, Sampson, Greenhill, Hobson, Jack. The rector of the university then delivered an address preliminary to conferring the honorary degrees. By the original charter of the university the power of bestowing such degrees had been withheld. For this celebration, however, special permission had been granted and to signalize the occasion further a new degree, Doctor Mathematicæ, was introduced. This distinctive degree was bestowed upon the following twenty-nine 
persons of whom the ten who were present went forward as their names were read and received their diplomas amid great applause :

Appell, Bäcklund, Boltzmann, G. Cantor, Cremona, Darboux, G. Darwin, Dedekind, Dini, Forsyth, J. W. Gibbs, Hilbert, Jordan, Lord Kelvin, Klein, Koenigsberger, Markov, Mittag-Leffler, Newcomb, Picard, Poincaré, Lord Rayleigh, Salmon, Schwarz, Stokes, Volterra, Weber, Wirtinger, Zeuthen.

Professor Newcomb made a short speech thanking the university on behalf of the recipients of the degree. The rector of the university delivered a peroration and declared the celebration officially at an end.

But for the delegates much was yet in store - perhaps the pleasantest part of all. Professor Bjerknes and his son took some of us who were especially interested in mechanics, among whom could be seen Volterra, Love, and Lamb, to his laboratory and showed us his apparatus specially devised for exhibiting his hydrodynamic action at a distance. In the evening the city of Christiania gave us a dinner, during and after which we had another excellent opportunity to renew or further our acquaintance with one another. This occasion was the climax of the celebration. A magnificent collation was served. The King and the various nationalities were toasted. Enthusiasm waxed to fever heat. Finally the students came in a torchlight procession under the windows of the banquet hall, greeting the delegates with prolonged and uproarious applause. On Sunday various excursion parties into the environs of Christiania were formed for our interest. Sunday evening there was a special representation of Ibsen's Peer Gynt at the national theater to which we had invitations. For the following Wednesday Professor Mittag-Leffler extended an invitation to lunch to such of us as might be in Stockholm.

By Monday evening most of us had left Christiania feeling that the celebration had been uncommonly successful : for the committee had accomplished the difficult task of making each succeeding event better than the previous one.

PARIS, September 25.

E. B. Wilson. 